\title{
Polymethyl methacrylate based open-cell porous plastics for high-pressure ceramic casting
}

\author{
Y. Ergün ${ }^{\mathrm{a}}$, C. Dirier ${ }^{\mathrm{b}}$, M. Tanoğlu $\mathrm{u}^{\mathrm{c}, *}$ \\ ${ }^{a}$ Material Science and Engineering Program, İzmir Institute of Technology, Gülbahçe Campus, Urla, 35437 İzmir, Turkey \\ ${ }^{\mathrm{b}}$ Ege Vitrifiye Sanitaryware Inc., Ankara Karayolu, Kemalpasa, 35170 İzmir, Turkey \\ ${ }^{\mathrm{c}}$ Department of Mechanical Engineering, Materials Research Center, Izmir Institute of Technology, \\ Gülbahçe Campus, Urla, 35437 İzmir, Turkey
}

Received 30 October 2003; received in revised form 17 June 2004

\begin{abstract}
The aim of the present study is to investigate the microstructure-property relation in polymethyl methacrylate (PMMA)-based porous mould materials used for high-pressure casting of ceramic articles. For this purpose, porous plastic materials were produced by the polymerization of water-in-oil emulsions with various compositions of emulsion constituents and particle sizes of the filler PMMA beads. Pore morphology, porosity and water permeability of the materials were measured. The compressive stress-strain behavior, collapse stress and elastic modulus values of the macroporous materials were determined by performing compressive mechanical testing. Fracture toughness values of the materials were also measured using the single-edge notched bending method. The results showed that the concentration of emulsion constituents and PMMA bead sizes has significant effects on the pore morphology, porosity, water permeability and mechanical properties of the porous plastics.
\end{abstract}

(C) 2004 Elsevier B.V. All rights reserved.

Keywords: Porous plastics; Polymethyl methacrylate; Ceramic casting

\section{Introduction}

Traditionally, the slip casting process for shaping of ceramic sanitaryware and whiteware articles has been performed using a material called plaster of Paris. This material has an open cell structure with a mean pore size of about $1 \mu \mathrm{m}$ and it operates under the principle of capillarity to absorb water from the ceramic slip. Plaster moulds are inexpensive, suitable for machining and operated without external pressure. However, they exhibit long casting periods (1-2h), long drying time and have limited service life due to their low wear resistance (80-100 maximum casts). Moreover, cast part contains high amount of water that has to be removed by drying with some additional cost.

\footnotetext{
* Corresponding author. Tel.: +90-232-750-6597; fax: +90-232-750-6505.

E-mail address: metintanoglu@iyte.edu.tr (M. Tanoğlu).
}

To overcome the limitations of plaster of Paris and improve the ceramic article quality and productivity, the trend in ceramic industry is the utilization of high pressure automated casting processes. In this technique, a porous mould material that allows the drainage of the water from the slip under high pressures of typically 13-15 bar is needed [1]. The materials with an open cell structure must show high water permeability, high mechanical strength and fatigue performance. These materials are also expected to keep their structural integrity without deformation and to allow using high pressures to provide a tight seal around the mold without cracking for about 20,000 cycles.

Polymeric materials, especially polymethyl methacrylate (PMMA)-based porous materials, became the most suitable class of materials for this purpose. Using this type of materials, the casting and demolding period can be shortened up to $20 \mathrm{~min}$, moulds require no drying between the casting cycles since an air-purging system is used for dewatering and 
therefore mold can be returned to the service immediately. Furthermore, the casting period can be adjusted by changing the slip pressure within the limits of the mechanical strength of the mould material. However, the service life and performance of plastic moulds is closely related to the microstructure and mechanical properties of the material. Therefore, fundamental understanding of the processing, microstructure and property relationship in these materials is essential to obtain optimized performance. To our knowledge, there is very limited work reported in the literature about the subject. In some recent studies, it was attempted to improve the mechanical performance of the porous moulds by addition of reinforcing components such as clay particles into the plastic structure [2-4].

In this study, plastic materials with various pore morphologies were produced by polymerization of water-in-oil emulsions with various compositions of the emulsion constituents and particle sizes of the PMMA beads. The effects of changing the compositions and bead sizes on the pore fraction and morphologies were investigated by scanning electron microscopy (SEM) and optical microscopy techniques. Also the relation between the morphology, water permeability and mechanical properties of the porous materials was investigated. Compressive mechanical testing was performed to obtain the stress-strain behavior, elastic modulus and collapse stresses of the samples. Additionally, fracture toughness values of the materials were measured based on single-edge notch bending (SENB) test.

\section{Experimental procedure}

\subsection{Materials}

The porous plastic materials were produced by the polymerization of water-in-oil emulsions from hardenable compositions that contains monomer of methyl methacrylate (MMA), spherical PMMA beads, initiator, emulsifier (surfactant) and water. PMMA beads with average bead sizes in the range of 22 and $150 \mu \mathrm{m}$ were used as filler material. Benzoyl peroxide (BPO) was used as polymerization initiator. To provide homogeneity and stability of the emulsion a watersoluble non-ionic surfactant of ethylene oxide-propylene oxide (EO-PO) block-copolymer was used.

\subsection{Production of porous plastic materials}

To produce the PMMA-based porous materials, water-inoil emulsions were prepared using the emulsion constituents with the following concentrations. The water phase contained the finer PMMA beads (20-30 wt.\%) and the surfactant. During the preparation of emulsions, the water-surfactant ratio was kept constant while their total concentrations varied between 30 and $40 \mathrm{wt} . \%$. The oil phase contained the coarser beads (15-25 wt.\%), benzoyl peroxide (0.3-0.5 wt.\%) and methyl methacrylate monomer (15-20 wt.\%). The oil phase was stirred shortly and the blend formed a viscous fluid of polymer in monomer due to the absorption of MMA by PMMA beads. Finally, the oil and water phases were mixed together to form the water-in-oil emulsions. Stable emulsions were cast on an epoxy mold to form the final porous materials. After polymerization, water was removed from the final product and the described technique resulted in randomly distributed open cell structure.

\subsection{Characterization of the porous plastic materials}

Optical and scanning electron microscopy was used to investigate the pore morphology of the materials, and threshold of the optical micrographs was analyzed using an image analyzer software to determine the areal fraction of porosity.

The water permeability of the samples was measured using a custom-made cylindrical permeability apparatus, with a diameter of $80 \mathrm{~mm}$ and depth of $20 \mathrm{~mm}$. A pressure of $4 \mathrm{bar}$ was applied on the samples and the volume of water permeated per unit volume was recorded. The permeability constant $\kappa$ was calculated by the equation of Henry Darcy [5], which describes the flow through porous media, as shown below

$\frac{Q}{A}=\frac{\kappa}{\eta} \frac{\Delta P_{\mathrm{e}}}{L}$

where $Q$ is the volume of liquid permeated per unit time, $A$ is the cross sectional area of the sample, $\eta$ is the viscosity of the fluid, $\Delta P_{\mathrm{e}}$ is the external driving pressure, $L$ is the thickness of the sample and $\kappa$ is the permeability constant.

Compressive mechanical tests were performed on the various porous materials to investigate the effect of the pore morphology on the mechanical behavior of the materials. Specimens with $15 \mathrm{~mm}$ diameter and $20 \mathrm{~mm}$ length were sectioned from larger slabs and all the specimens were dried at $35^{\circ} \mathrm{C}$ for $24 \mathrm{~h}$ prior to testing. At least five specimens from each set were tested at room temperature under a constant crosshead speed of $1.3 \mathrm{~mm} / \mathrm{min}$, using a Shimatzu ${ }^{\mathrm{TM}}$ universal testing machine. Friction between the compression plates and the specimen surfaces was reduced by lubricating the plate surfaces lightly with anti-friction grease.

The fracture toughness $\left(K_{\mathrm{IC}}\right)$ of the porous materials were measured according to ASTM D5045-91 a standard [6], based on the single-edge notch bend specimen configuration. Specimens with the thickness of $6 \mathrm{~mm}$ and width of $12 \mathrm{~mm}$ were prepared by sectioning from larger slabs using a diamond saw. On one edge of the specimens, a notch was opened by machining with a rotating abrasive disc and a sharp pre-crack was formed by simply pressing a sharp razor blade into the notched region [7]. All specimens were dried at $35^{\circ} \mathrm{C}$ for $24 \mathrm{~h}$ and toughness testing was done at room temperature. Testing was performed using a crosshead speed of $10 \mathrm{~mm} / \mathrm{min}$. The $K_{\text {IC }}$ values were calculated based on the following equation in units of $\mathrm{MPa} \mathrm{m}^{1 / 2}$

$K_{\mathrm{IC}}=\left(P_{\mathrm{Q}} B W^{1 / 2}\right) f(x)$ 


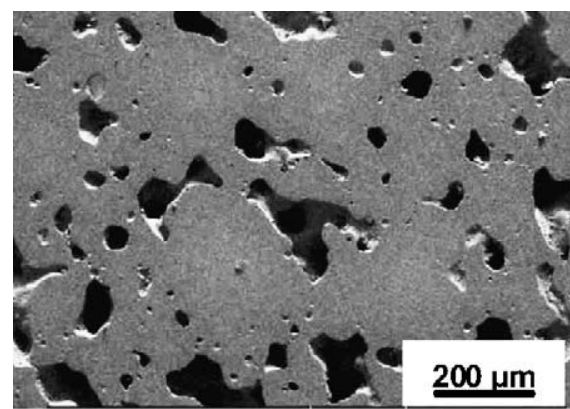

(a)

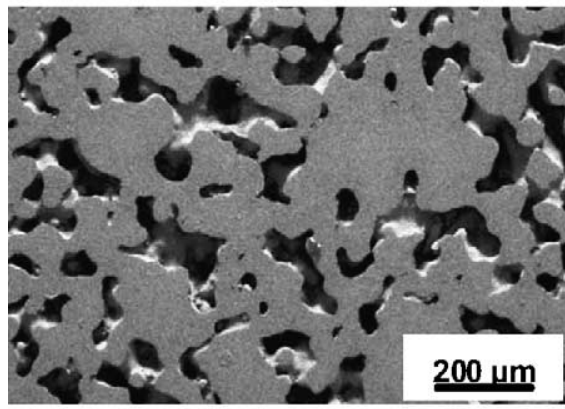

(b)

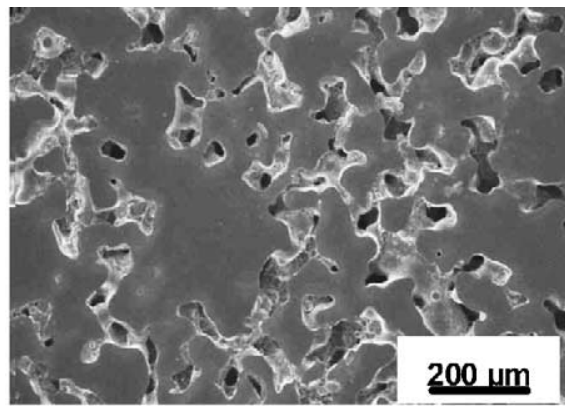

(c)

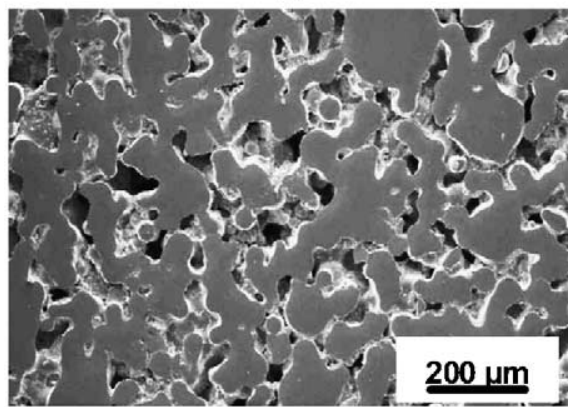

(d)

Fig. 1. SEM polished surface micrographs of PMMA-based plastics produced with various concentrations of surfactant-water. The total weight fraction of water and surfactant in the emulsions are: (a) 29 wt. \%; (b) 33 wt.\%; (d) 37 wt.\%; (d) 40 wt.\%.

In the equation, $P_{\mathrm{Q}}, B, W$ and $f(x)$ are load, specimen thickness, specimen width and a calibration factor, respectively.

\section{Results and discussion}

PMMA-based porous plastics were produced with various concentrations of water-in-oil emulsion constituents. Fig. 1 shows the SEM images of the porous materials processed with varying total weight fraction of water and surfactant in the emulsions. The concentrations of these constituents in the emulsions were changed in the range of $29-40 \mathrm{wt} . \%$. The results showed that the pore fraction, morphology and cell connectivity are significantly affected by the total concentrations of water and surfactant. The ratio between the concentrations of liquid constituents: water-surfactant and monomer, defines the formation of the network and also connectivity of the cells. It was observed that the porosity and cell connectivity is increased as the concentrations of water-surfactant are increased. As illustrated in Fig. 1(a), at low concentrations of the water-surfactant, water droplets are completely enclosed by the oil phase and larger isolated pores were formed. At higher concentrations of these constituents, finer size pores with extended connectivity are observed as can be seen in Fig. 1(c) and (d). Note that the free radical polymerization reaction occurs in the oil phase between MMA molecules that are activated by phenyl free radicals, which are a decomposition product of BPO. Polymerized monomer molecules form the cell walls with the contribution of PMMA beads. The macropore structure is mainly formed by the water droplets surrounded with surfactants within the emulsion during the polymerization of the oil phase. As the polymerization is completed, the water phase is removed from the structure and an open-cell porous structure is left behind. Therefore, homogeneous distribution of the water droplets with high connection and the stabilization of the emulsion through out the polymerization reaction are essential to produce an optimized open-cell porous structure.

Fig. 2 shows the variation of porosity and permeability constant as a function of total weight fraction of surfactant and water. As can be seen in this figure, the percentage of the porosity increased from 34 to $47 \%$ as the amount of water-surfactant increased from 29 to $40 \mathrm{wt}$. $\%$, respectively. As the porosity and effective cell connectivity of the materials

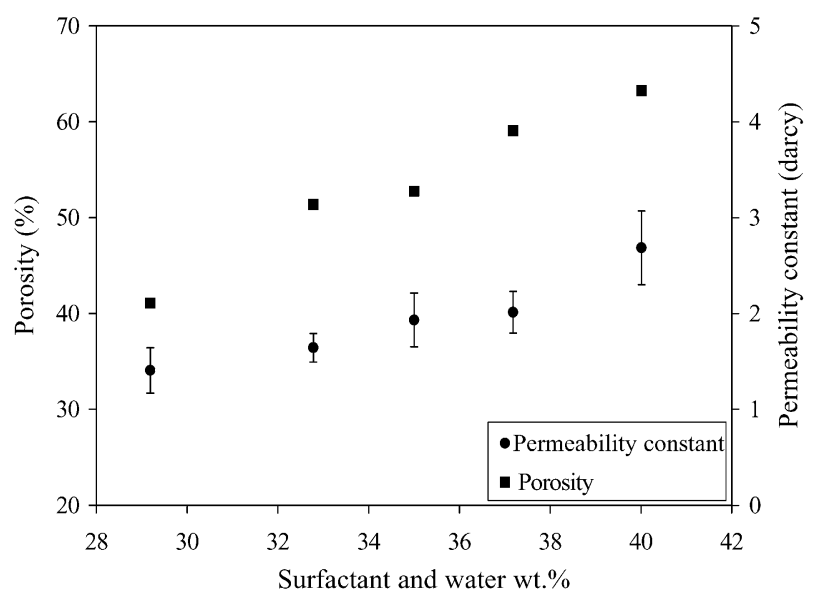

Fig. 2. Porosity and water permeability constant of the PMMA-based porous plastics with respect to surfactant and water concentrations. 
is increased, the permeability constant of the specimens was increased from 2.1 to 4.3 Darcy for the given concentration range.

Besides the water permeability, the mechanical performance of these materials is critical because high pressures cycles are applied during the shaping of ceramic articles. Mechanical behavior of porous materials during compressive loading is significantly affected by the pore structure. Fig. 3 shows the typical compressive stress-strain curve of a PMMA-based porous plastic mold material processed within this study. The material exhibits three distinct regions, similar to the compressive behavior of elastic brittle foams as described by Gibson and Ashby [8]. The first region is a linear elastic region that is controlled by cell wall bending and cell face stretching. The second region is a long deformation plateau with lower rate increasing stress values as compared to first region. Deformation in this region involves tearing and brittle crushing of the cells, progressive collapse of the pore network and plastic flow of the structure. This deformation plateau is generally described with an almost constant stress for open cell structure materials. With the collapse of the cells, opposing cell walls touch each other and further stress begins to compress the solid itself, and creates the final region of densification with a rapidly increasing stress (region III). The precise formation of the three-region behavior depends on the cell structure and the density of the material. The increase of stress level in the second region for the present case may be associated with the presence of a fraction of closed cells in the structure.

Fig. 4 shows the compressive stress-strain graphs of the samples produced with various concentrations of water and surfactants (29-40 wt.\%). The stress-strain behavior of all the specimens showed linear elasticity up to the collapse stress. The collapse stress $\left(\sigma_{\mathrm{c}}\right)$ is defined as the point at which deviation was observed in the linear part of the stress-strain curves as shown in Fig. 3. From the slope of the linear elastic region, modulus values were also calculated. Fig. 5 shows the variations in collapse stress and elastic modulus values with respect to water and surfactant concentrations. It was found

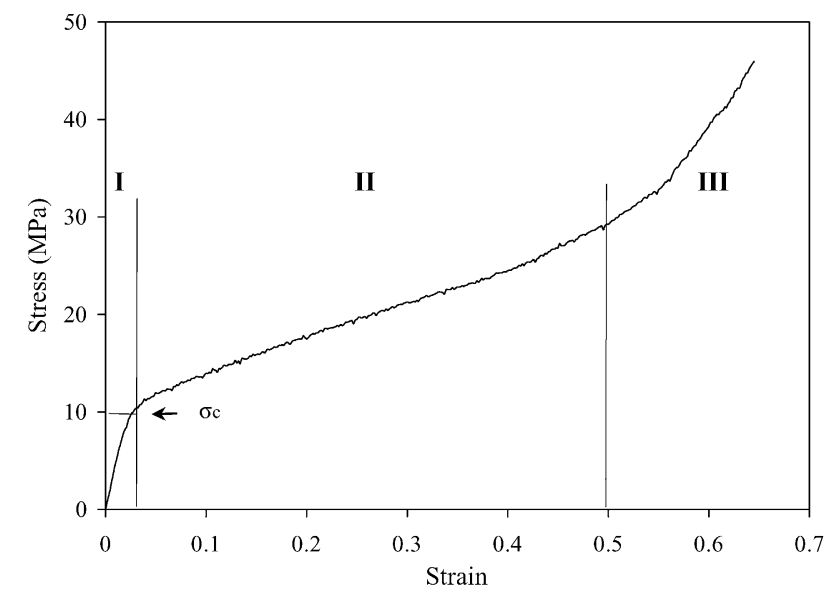

Fig. 3. Compressive stress-strain response of PMMA-based porous plastics.

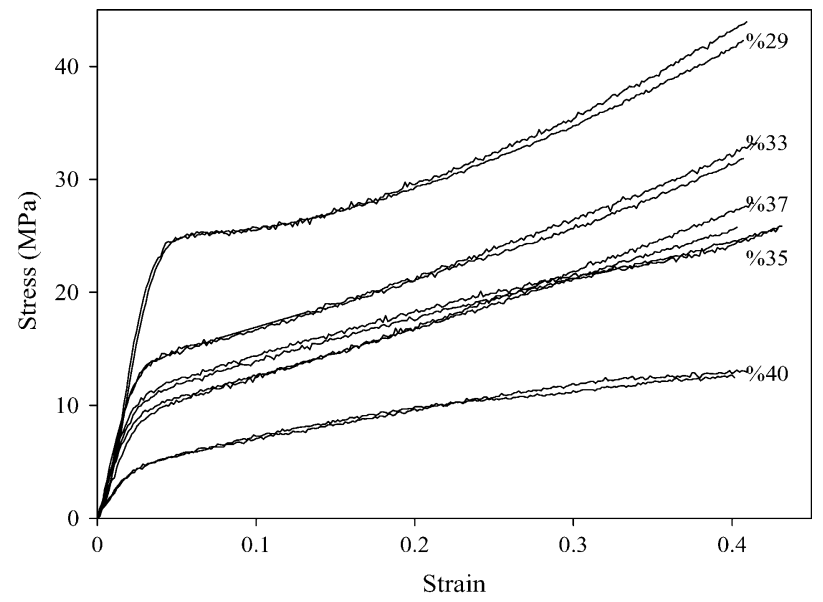

Fig. 4. Compressive stress-strain graphs of porous plastics with various surfactant and water concentration.

that the collapse stress and elastic modulus values decreases from 24 to 4.9 and 824 to $224 \mathrm{MPa}$, respectively, as the concentration of water-surfactant increases from 29 to $40 \mathrm{wt} . \%$. The reduction of the mechanical properties is related to the porosity increase from 34 to $47 \%$ for the given concentration range, respectively. Also, the densities of the tested materials changes from 0.803 to $0.762 \mathrm{~g} / \mathrm{cm}^{3}$ for the same concentration range. The material with a high density exhibited a short deformation plateau (in region II) in the stress-strain graphs. This is associated with lower porosity and higher fraction of closed cells. On the other hand, as shown in Fig. 4 material with a lower density has a longer deformation plateau, such that densification begins at much higher strain values. This is probably due to higher fraction of pores with open-cell structure that involves extensive progressive collapse of the pore network.

In addition to water-surfactant concentrations, the effects of monomer concentration and PMMA bead sizes on the properties were investigated. Figs. 6-9 show the variation of porosity and water permeability, and collapse stress and

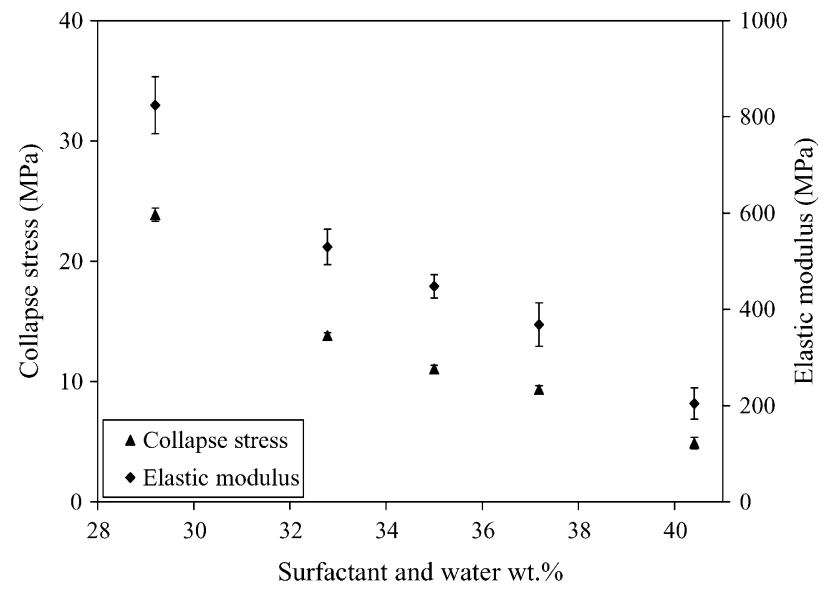

Fig. 5. Collapse stress and elastic modulus values with respect to surfactant and water concentrations. 


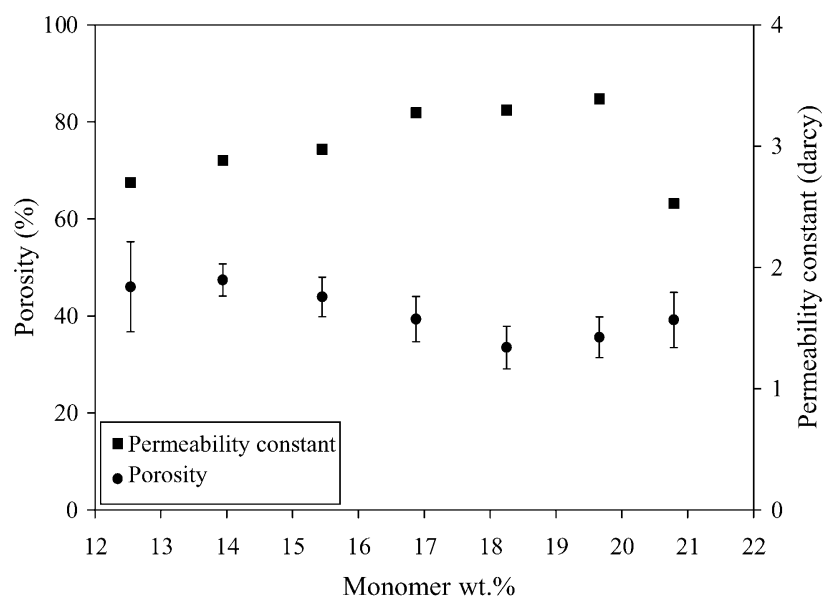

Fig. 6. Porosity and permeability constant with respect to monomer (MMA) concentrations.

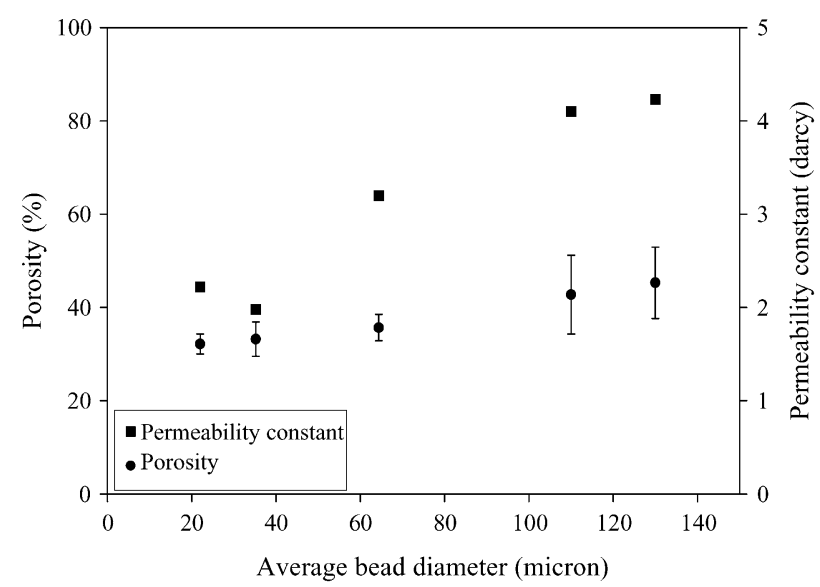

Fig. 7. Porosity and permeability constant with respect to average PMMA bead diameter.

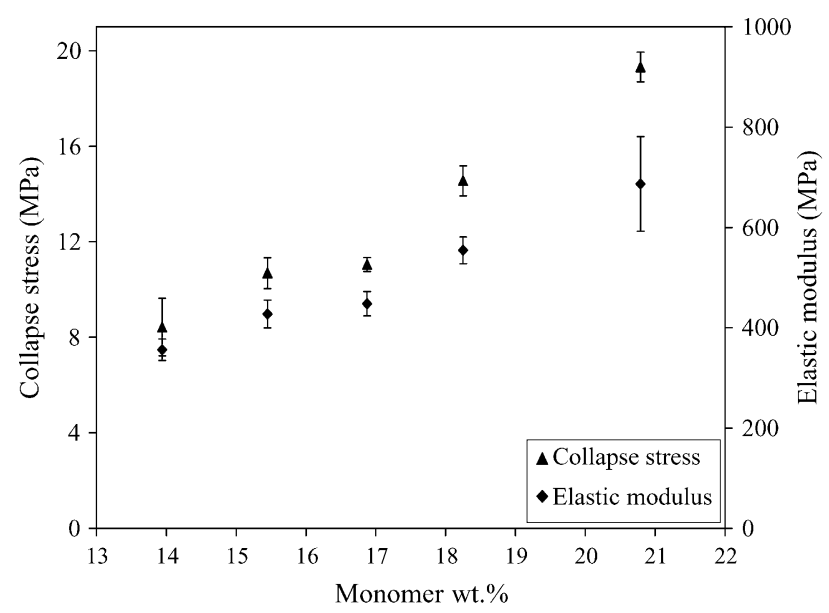

Fig. 8. Collapse stress and elastic modulus with respect monomer (MMA) concentrations.

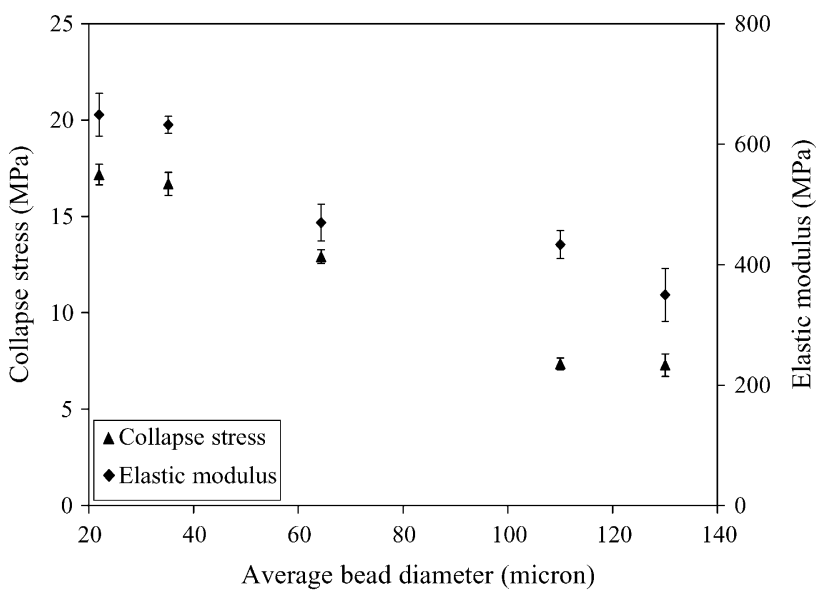

Fig. 9. Variation of collapse stress and elastic modulus with respect to average PMMA bead diameter.

modulus values as a function of monomer concentrations and bead diameters. It was found that with an increase in concentration of monomer up to $18 \mathrm{wt} . \%$, the porosity increases and permeability values decreases. The increase of monomer concentration in the same range results in increase of collapse stress and modulus values from 8.4 to 19.3 and 356 to $687 \mathrm{MPa}$, respectively. Similarly, porosity and permeability values increase from 32 to $45 \%$ and from 2.2 to 4.2 Darcy, respectively, as the average bead diameter changes from 22 to $150 \mu \mathrm{m}$. For the same variation of average bead diameters, collapse stress and modulus values decrease from 17 to 7.3 and 649 to $350 \mathrm{MPa}$, respectively. As discussed previously, polymerized monomer molecules form the cell walls with the contribution of PMMA beads and the porous network is mainly formed by the water droplets surrounded with surfactants. So, the increase of the mechanical properties with increased monomer amount or reduced bead sizes is due to the formation of thicker cell walls with higher strength.

The fracture toughness $\left(K_{\mathrm{IC}}\right)$ values of the materials were measured using the SENB test configuration and are tabulated for varying water-surfactant and monomer concentrations in Table 1. It was found that $K_{\mathrm{IC}}$ values decrease by $64 \%$ as the concentration of water-surfactant is increased by $38 \%$. In contrast, $K_{\mathrm{IC}}$ values increases by $104 \%$ as the

Table 1

Fracture toughness of materials produced with various water-surfactant and monomer concentrations

\begin{tabular}{lll}
\hline & wt.\% & $\begin{array}{l}\text { Fracture toughness } \\
\left(K_{\mathrm{IC}}, \mathrm{MPa} \mathrm{m}^{1 / 2}\right)\end{array}$ \\
\hline Water-surfactant & 29 & $0.376 \pm 0.005$ \\
& 33 & $0.219 \pm 0.041$ \\
& 35 & $0.187 \pm 0.006$ \\
& 37 & $0.180 \pm 0.010$ \\
Monomer (MMA) & 40 & $0.134 \pm 0.026$ \\
& 15.5 & $0.158 \pm 0.006$ \\
& 18.3 & $0.246 \pm 0.017$ \\
& 19.7 & $0.274 \pm 0.016$ \\
& 20.8 & $0.322 \pm 0.016$ \\
\hline
\end{tabular}




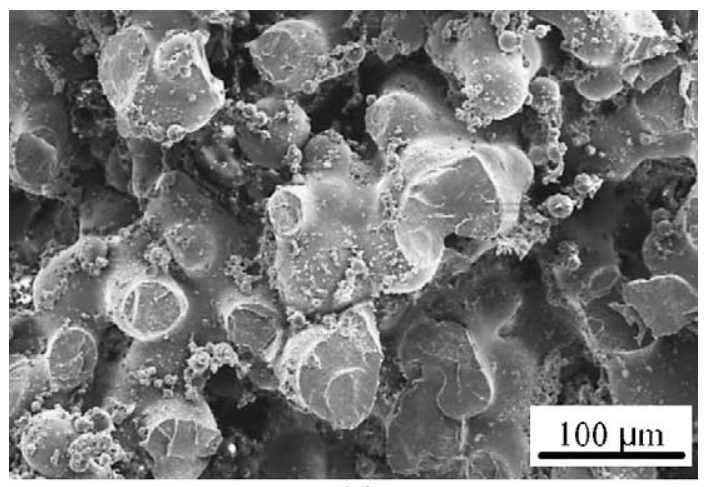

(a)

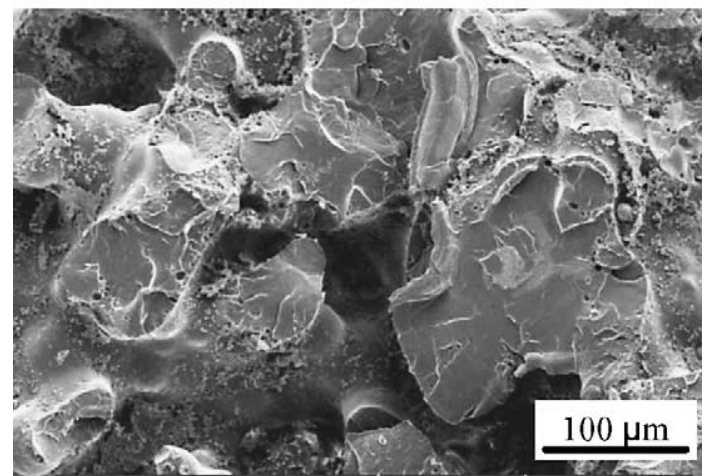

(b)

Fig. 10. SEM fracture surface micrograph of porous materials produced with 40 wt. $\%$ (a) and 29 wt.\% (b) of water and surfactant.

monomer concentration is increased by $34 \%$. The results indicate that $K_{\mathrm{IC}}$ is increasing as the pore fraction is decreasing and cell walls are thickening. Fig. 10 shows the SEM fracture surface micrograph of the SENB specimens with 40 and 29 wt. \% water-surfactant, respectively. A high concentration of water-surfactant in the emulsion resulted in an increase of pore fraction and reduction of the thickness of the cell walls as can be seen in Fig. 10(a). For this case, fracture occurs over a relatively smaller area by the tear of thinner cell walls. There is no noticeable plastic deformation on the fracture surfaces. For lower concentration, as shown in Fig. 10(b), the porosity is lower and thicker cell walls formed where the filler PMMA beads are completely embedded into the monomer phase, dissolved in it and connected very strongly. Fracture occurs over a larger area and for the extension of the crack a higher surface energy is required. This may result in improved fracture toughness of the material with a higher $K_{\mathrm{IC}}$ values. On the other hand, an increase in MMA concentration resulted in a significant increase of the fracture toughness values due to the formation of a low fraction of pores and relatively thicker cell walls with higher strength. Fig. 11 shows the SEM fracture surfaces of SENB samples produced with monomer concentrations of 15.5 and $20.8 \mathrm{wt}$.\%, respectively. Similarly, as the concentration of MMA is increased as in Fig. 11(b), much thicker cell walls forms and fracture occurs over a large area.

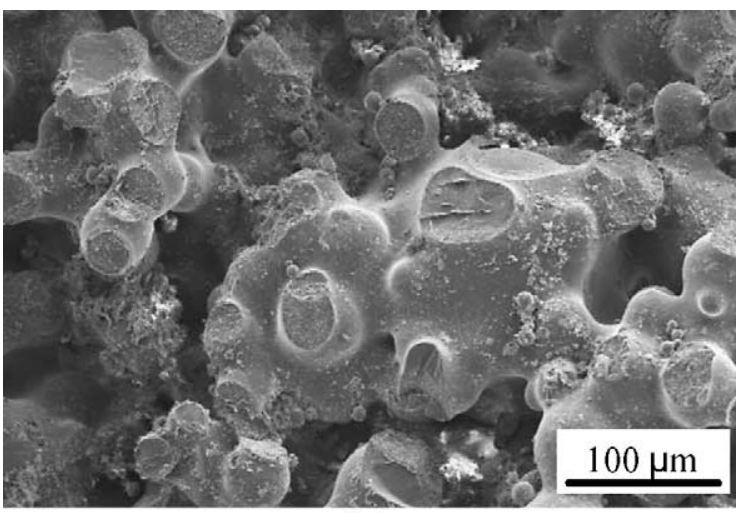

(a)

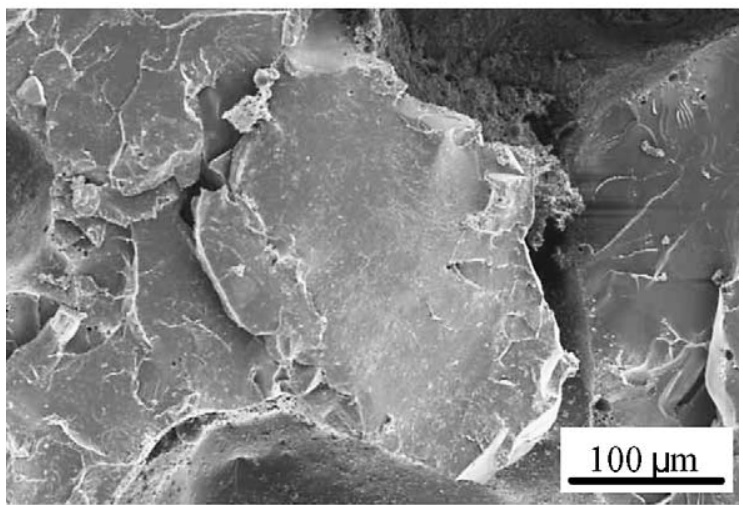

(b)

Fig. 11. SEM fracture surface micrograph of porous materials produced with 15.5 wt. \% (a) and 20.8 wt.\% (b) of MMA monomer.

\section{Conclusions}

PMMA-based open-cell porous materials were produced using various concentrations of water-in-oil emulsion constituents and PMMA bead sizes. It was revealed that the porous network is mainly formed by the water droplets surrounded with surfactants and the cell walls are formed by the polymerized monomer molecules with the contribution of PMMA beads. To produce an optimized open-cell porous structure, it is essential to obtain homogeneous distribution of the water droplets with high connection and the stabilization of the emulsion through out the polymerization reaction. It was found that constituent concentrations significantly affect the porosity, pore morphology, water permeability, collapse stress and elastic modulus of the porous plastics. The percentage of the porosity increased from 34 to $47 \%$, the permeability constant of the specimens was increased from 2.1 to 4.3 Darcy as the amount of water-surfactant increased from 29 to $40 \mathrm{wt} \%$, respectively. Mechanical testing of the macroporous samples showed that the material exhibits the compressive behavior similar to elastic brittle foams. It was found that the collapse stress, elastic modulus and $K_{\text {IC }}$ values decreases as the concentration of water-surfactant increases. The reduction of the mechanical properties is mainly related to the increase of porosity and formation of thin cell walls. Similarly, it was found that porosity and permeability values 
increase, collapse stress and modulus values decrease as the larger diameter beads are used.

\section{Acknowledgements}

The authors acknowledge Ege Vitrifiye Sanitaryware Inc. of Turkey for the financial support. The authors also wish to thank C. Tokman, C. Dirier, M. Yılmaz and E. Erdoğan of Ege Vitrifiye Sanitaryware Inc.

\section{References}

[1] V. Mazzanti, Process. Eng. DKG 79 (1-2) (2002) 11-12.
[2] A. Dortmans, H. Fischer, R.G. Nelissen, Process Eng. DKG 79 (1-2) (2002) 45-48.

[3] A. Dortmans, L.F. Batenburg, T.P.M. Koster, R.G. Nelissen, H. Fischer, e-Polymers 10 (2002) 1-10 (http://www.e-polymers.org).

[4] E.J. Pique, L.J.M.G. Dortmans, G. de With, Mater. Sci. Eng. A 335 (2002) 217-227.

[5] R.J. Stokes, D.F. Evans, Fundamentals of Interfacial Engineering, Wiley-VCH, New York, USA, 1997.

[6] Standard Test Methods for Plane-Strain Fracture Toughness and Strain Energy Release Rate of Plastic Materials, American Society for Testing and Materials (ASTM) D5045-91a.

[7] T.L. Anderson, Fracture Mechanics: Fundamentals and Application, second ed., CRC Press, New York, USA, 1995.

[8] L.J. Gibson, M.F. Ashby, Cellular Solids, , second ed., Cambridge University Press, Cambridge, UK, 1997. 